\title{
Desenvolvimento, antropologia e "participação". Uma proposta de reflexão crítica
}

\section{Roberto Salviani}

\section{(2) OpenEdition}

1 Journals

Edição electrónica

URL: http://journals.openedition.org/aa/840

DOI: $10.4000 / a a .840$

ISSN: 2357-738X

Editora

Programa de Pós-Graduação em Antropologia Social (UnB)

\section{Edição impressa}

Data de publição: 1 junho 2010

Paginação: 227-261

ISSN: 0102-4302

\section{Refêrencia eletrónica}

Roberto Salviani, «Desenvolvimento, antropologia e "participação". Uma proposta de reflexão crítica», Anuário Antropológico [Online], v.35 n.1 | 2010, posto online no dia 13 outubro 2015, consultado o 28 abril 2021. URL: http://journals.openedition.org/aa/840 ; DOI: https://doi.org/10.4000/aa.840

\section{(c) $)(1)(9$}

Anuário Antropológico is licensed under a Creative Commons Atribuição-Uso Não-Comercial-Proibição de realização de Obras Derivadas 4.0 International. 


\title{
Desenvolvimento, antropologia e "participação". Uma proposta de reflexão crítica
}

\author{
Roberto Salviani \\ LACED/ Museu Nacional/UFRJ
}

\section{Introdução}

Neste artigo tentamos refletir sobre alguns aspectos da relação entre antropologia e "campo do desenvolvimento" por meio da análise de algumas das contribuições para a formulação de técnicas de intervenção neste campo, oriundas da disciplina antropológica e das críticas às mesmas.

Depois de uma rápida introdução relativa aos principais enfoques que norteiam os estudos antropológicos do "campo do desenvolvimento" e à relação dos antropólogos com ele, voltaremos nossa atenção para a origem das técnicas participativas e a trajetória da sua inserção em discursos e práticas desenvolvimentistas. Ao longo da exposição, veremos como o(s) conceito(s) de “participação" faz(em) parte de um conjunto de termos e formulações que parecem ter adquirido grande relevância nos discursos desenvolvimentistas, (p. ex., "indigenous knowledge" e "empowerment"). Ao percorrer a produção relativa, veremos como as relações entre "participação", "conhecimento" e "poder" acham-se articuladas principalmente com dois enfoques "participativos": o do Banco Mundial, (desenvolvido, sobretudo, a partir do trabalho de Michael Cernea), e aquele do conjunto de técnicas que constituem o Participatory Rural Appraisal (PRA) cujo maior proponente a ser considerado é Robert Chambers (ver nota 7) - enfoques que ocupam a parte central da análise.

A escolha do Banco Mundial como cerne da discussão justifica-se, a nosso ver, pelo papel de liderança que esta instituição adquiriu no campo institucional do desenvolvimento, ou seja, entre "atores" institucionais como bancos e agências multilaterais, bilaterais e nacionais de desenvolvimento. De fato, apesar de limitarmos a análise a uma única instituição, pensamos que a argumentação deva manter certa validade geral.

De determinado ponto de vista, o Banco Mundial (a partir de agora simplesmente o "Banco") é um dos maiores responsáveis pela atual proximidade de antropólogos com o campo do desenvolvimento. O conspícuo incremento do número de antropólogos (entre outros cientistas sociais), chamados para integrar Agências 
e Instituições de desenvolvimento, pode ser considerado a consequência de uma “mudança de paradigma” - "paradigm shift" (Cooper \& Packard, 1997:19) - no campo desenvolvimentista. Tal mudança, referida como New Directions, ${ }^{2}$ se deu ao longo dos anos 70, e tem o Banco como um dos principais agentes. Reconhecendo a necessidade de considerar as determinantes sociais que influenciam a implementação das intervenções, as New Directions abrem espaço para uma maior participação dos cientistas sociais (além dos economistas), e seus conhecimentos parecem assim adquirir maior peso para determinar a possibilidade de uma implementação sucessiva de planos e projetos de desenvolvimento. Em outras palavras, através do novo paradigma, o "social" entra no campo do desenvolvimento, onde antes reinavam somente o "técnico" e o "econômico."

Martha Finnemore (1997), nos mostra o peso determinante do Banco (desde a gestão McNamara, 1968) na institucionalização dessa mudança de paradigma em direção ao "basic needs approach": "The goal of poverty alleviation become institutionalized as part of the international development effort. The driving force behind this new understanding of development was the World Bank" (Finnemore, 1997:208). ${ }^{3}$ Um número sempre maior de antropólogos foi chamado para fazer parte das agências de desenvolvimento (Stirrat, 2000:32; Eyben, 2000:9; Francis \& Jacobs, 1999:22 apud Mehta, 2001:194), ao mesmo tempo, aumenta drasticamente o número de profissionais desta área contratados na condição de consultores. ${ }^{4}$ Como consequência, ao longo dos anos 80, a "development anthropology", que podemos traduzir como "antropologia para o desenvolvimento", ganha uma consistência notável no campo dos estudos antropológicos (Henkel \& Stirrat, 2001:169). Esta antropologia ocupa-se da dimensão nativa dos contextos de desenvolvimento, tomando como objeto o "local”, o "grupo-alvo" e as relações entre as características socioculturais destes e as dimensões institucionais dos "projetos".

Existem diferenças marcadas nas metodologias e nos objetivos no interior do campo da antropologia para o desenvolvimento, isto é, a antropologia aplicada às ações de mudança social induzida,${ }^{5}$ e tais diferenças derivam sobretudo de leituras, interpretações e posturas diferenciadas do campo das relações políticas que usualmente vêm sendo subordinadas às relações econômicas. Assim, entre as propostas de aplicação das disciplinas sociológicas às atividades de desenvolvimento no âmbito do Banco, encontramos um conjunto variado de técnicas que vão desde a apropriação da "engenharia social” por Michael Cernea $(1983,1991)$ ao "Participatory Rural Appraisal” (PRA) de Robert Chambers (1995), ${ }^{7}$ das quais nos ocuparemos aqui, tentando formular críticas e reflexões relativas a estas posturas teórico-metodológicas. ${ }^{8}$

Outro enfoque antropológico relativo ao "desenvolvimento" vem tomando corpo, todavia, nos últimos anos. Esta perspectiva tem como foco, sobretudo, as ideias 
e as práticas daqueles que planejam e executam os projetos, ocupando-se em indagar a sua proveniência e os seus efeitos. Henkel e Stirrat (2001:169) definem este campo como "antropologia do desenvolvimento", cujo foco de atenção concentra-se na empresa do desenvolvimento como fenômeno social, resultado da conjunção entre saberes e técnicas de dominação particulares, no contexto mais amplo das relações de poder que incidem nas imagens e nas configurações do mundo contemporâneo. Uma parte desses trabalhos trata o "campo do desenvolvimento" (desde agora sem aspas) como campo de práticas discursivas e, valendo-se sobretudo dos instrumentos de análise propostos por Foucault (1971), tenta entender as relações existentes entre "discursos" e "práticas" no campo do desenvolvimento, e os efeitos de poder dos mesmos (e.g. Ferguson, 1990; Escobar, 1995).

Nossa discussão será centrada na "participação", um dos fenômenos mais evidentes na história "recente" do desenvolvimento (Ranhema, 1992; Nelson \& Wright, 1995. Cf. Banco Mundial, 1994), cujo sucesso neste campo levou vários autores a defini-la como a nova "ortodoxia" desenvolvimentista (cf. Stirrat, 1996; Green, 2000; Cooke \& Kothari, 2001). Esboçaremos brevemente as raízes das técnicas participativas para nos ocuparmos depois do conceito na sua relação com o campo do desenvolvimento em geral, e no Banco em particular.

\section{As técnicas participativas}

O início do desenvolvimento das técnicas participativas pode ser reconduzido ao contexto das formulações de Kurt Lewin (1946) relativas à Pesquisa Ação. ${ }^{10} \mathrm{~A}$ pesquisa-ação lewiniana deu partida para a construção de novas e diferenciadas abordagens a esta problemática, conforme o objeto e os objetivos da pesquisa, ${ }^{11}$ que se modificam também de acordo com o contexto geopolítico de aplicação.

A pesquisa-ação participativa (PAR) representa um modelo crítico de pesquisaação utilizado especialmente na América Latina através do trabalho de Paulo Freire (1970) e Orlando Fals Borda (1981), e que se dirige mais à "emancipação" das populações objeto de estudo do que à pesquisa em si.

A pesquisa participativa gera uma metodologia em parte paralela àquela da pesquisa-ação clássica, porém, voltada a sujeitos-objetos de estudo completamente diversos daqueles da pesquisa-ação, buscando objetivos diferentes e fazendo explícita a referência à estreita ligação entre a metodologia e seus efeitos sociais.

A pesquisa participativa chama os atores sociais - objeto da pesquisa - para assumirem o papel de copesquisadores. Estes contribuem ativamente no delineamento do modelo e dos objetivos da pesquisa. Tal resultado é obtido através da presença do pesquisador que, em certa medida, deveria adotar uma postura similar àquela da observação participante. ${ }^{12}$ Seu papel consiste em conferir "legitimidade 
científica" às experiências pessoais, aos conhecimentos populares e aos outros modos de saber considerados como "não-científicos", como as formas de literatura oral e os modelos perceptivos locais. O conhecimento é assumido como um instrumento de poder e, portanto, o fim da pesquisa participativa consiste em conectar a produção do conhecimento à conscientização e à emancipação (self-reliance) do povo. A "participação" constitui-se assim enquanto conceito central da metodologia. Como afirma um dos pais da metodologia, Paulo Freire, o objetivo do trabalho de pesquisa não é medir e/ou descrever características de situações particulares para permitir a manipulação da realidade, mas operar uma ação cognitiva junto aos pressupostos objetos da prática experimental:

La investigación de los "temas generadores" o de la temática significativa del pueblo, al tener como objetivo fundamental la captación de sus temas básicos, a partir de cuyo conocimiento es posible la organización del contenido pragmático para el desarrollo de cualquier acción con él, se instaura como el punto de partida del processo de acción, entendida como síntesis cultural.

De ahí que no sea posible dividir en dos los momentos de este proceso: el de la investigación temática y el de la acción como síntesis cultural.

Esta dicotomía implicaría que el primero sería un momento en que el pueblo sería estudiado, analizado, investigado, como un objeto pasivo de los investigadores, lo que es propio de la acción antidialógica.

De este modo, la separación ingenua significaría que la acción, como síntesis, se iniciaría como una acción invasora.

Precisamente, dado que en la teoría dialógica no puede darse esta dicotomización, la investigación temática tiene, como sujetos de su proceso, no sólo a los investigadores profesionales, sino también a los hombres del pueblo cuyo universo temático se busca encontrar (Freire, 1970:238-9, grifo no original).

Algumas das técnicas de pesquisa (entre as quais moldar a ação) derivadas desta tradição teórica têm conquistado preponderância no campo do desenvolvimento. Entre estas, Beneficiary Assessment (BA), Social Assessment (SA), Environmental Assessment (EA), Rapid Rural Appraisal (RRA) e Participatory Rural Appraisal (PRA) representam as mais usadas na produção do Banco, e outras, como Participatory Action Research (PAR) e Participatory Learning Analysis (PLA) têm ampla difusão. ${ }^{13}$

Mas o que é, exatamente, a "participação" no campo do desenvolvimento? O que significa participar? Quais práticas podem ser definidas como participativas? Quem é que participa, e em quê? 


\section{A "participação" no desenvolvimento}

A "participação", longe de representar uma novidade no campo da cooperação ao desenvolvimento, detinha certa popularidade já nos esquemas de desenvolvimento comunitário dos anos 60 e 70 (Ranhema, 1992:117; Stone, 1989:207; Peters, 1996:22), e já estava presente na retórica do New Deal dos anos 30 (Eyben \& Ladbury, 1995:192).

A palavra "participação", como adverte Ranhema (1992:116), é parte de um conjunto de termos notavelmente plásticos, cujos significados devem ser contextualizados para que adquiram um conteúdo, prestando-se, caso contrário, a várias manipulações e ao uso retórico dos mesmos (Nelson \& Wright, 1995:7). Linda Stone (1989), por exemplo, valendo-se de sua própria experiência no Nepal, questiona a possibilidade da aplicação, em contextos culturais diferenciados, do conceito de "participação comunitária”, pondo em destaque as pressuposições culturalmente determinadas que ele carrega. A autora demonstra como as ideias relativas à "participação", assim como são formuladas pelos integrantes do projeto - objeto da sua pesquisa - diferem notavelmente das concepções dos "beneficiários", cuja compreensão sobre ela baseia-se sobretudo em experiências passadas com projetos e atividades de desenvolvimento. $\mathrm{O}$ quadro destas diferenças complica-se ainda mais pelo fato de que as várias agências e organizações não compartilham as mesmas definições e práticas (Hildyard et al., 2001:56), e no interior delas, os membros não raramente detêm posições que não coincidem entre si (Nelson \& Wright, 1995:7; Kaufmann, 1997:145-6).

Muitos autores que se ocupam em investigar o uso das técnicas participativas indicam que a principal diferença entre as várias concepções de "participação" empregadas no campo do desenvolvimento consiste em considerá-la enquanto: 1. meio para alcançar maior efetividade nos projetos e nas atividades de desenvolvimento; 2. resultado e fim em si mesmo (e.g. Nelson \& Wright, 1995; Peters, 1996; Green, 2000; Hildyard et al., 2001; Cooke \& Kothari, 2001).

Grande parte dos teóricos e praticantes das abordagens participativas consideram estas técnicas principalmente como instrumentos para fornecer maiores níveis e modalidades de controle social aos atores envolvidos em projetos de desenvolvimento. Neste sentido, a natureza da "participação" é determinada especialmente pelo grau de influência dos beneficiários na definição do tipo de atividade a ser implementada, e pelo grau de controle exercido por estes sobre cada uma delas.

A multiplicidade de significados e usos da "participação", isto é, a sua polissemia, é largamente reconhecida. Nesse sentido, vários pesquisadores têm desenvolvido sistemas de classificação das formas participativas, como mostra Michener (1998:2106ss), na tentativa de precisar definições. Por exemplo, segundo 
Deshler e Sock (1985 apud Michener, 1998:2106), as diferentes modalidades de "participação" podem ser divididas entre "genuine" e "pseudo-participation”. A "genuine participation" pode dar lugar a situações variadas, que vão desde efeitos de "empowerment" ${ }^{14}$ através do qual os cidadãos ganham controle direto sobre as atividades dos projetos, até "cooperation", que compreende "partnership" e "delegated power”. A "pseudo-participation”, ao contrário, é instrumental para as práticas de "assistencialism" e "domestication", podendo dar lugar, na melhor das hipóteses, a processos de consulta e extração de informações, e na pior, a mecanismos de manipulação (ibidem).

O esquema classificatório apresentado por White (1996, apud Michener, 1998:2107) prevê quatro formas de "participação": "nominal", "instrumental", "representative" e "transformative". As funções atribuídas a elas dependem dos divergentes interesses dos "stakeholders", que podem ser "top-down" ou "bottomup". O autor, desta forma, quer chamar a atenção para o fato de que podem existir diferentes perspectivas sobre as mesmas práticas participativas, como vimos com Linda Stone (1989). As diferenças entre as duas perspectivas, contudo, são eliminadas no nível das formas "Transformativas", no qual a "participação" tem efeitos de "empowerment" para ambas as visões ("top-down" e "bottom-up"), revestindo funções seja de meio, seja de fim.

Outra proposta de classificação das formas de "participação" (Cohen \& Uphoff, 1980 apud Michener, 1998:2107) busca ser mais compreensiva. Ao pretender distinguir as diferentes dimensões de "participação" em projetos de desenvolvimento rural, os autores reconhecem variadas áreas de "participação" "participation in decision making", "participation in implementation", "participation in benefits", "participation in evaluation"), diversos atores que participam ("local residents", "local leaders", "government personnel" e "foreign personnel") e os modos em que ela ocorre ("basis of participation", "form of participation", "extent of participation" e "effect of participation").

As modalidades de "participação", portanto, podem compreender um vasto raio de situações. No entanto, a "genuine participation" ocorre somente quando o resultado é o "empowerment" dos beneficiários, e é este o objetivo declarado de quem pratica o "Participatory Rural Appraisal” (PRA).

Os praticantes do PRA postulam uma estreita conexão entre "participação" e "empowerment" dos mais pobres, afirmando que as únicas abordagens que podem ser consideradas participativas são aquelas que levam ao efetivo "empowerment" dos grupos-alvo" (Chambers, 1995:39). A chave para que as práticas do PRA sejam bem-sucedidas e alcancem este resultado está mais na capacidade dos "pratictioners” em assumirem uma postura que reverta os papéis de pesquisador e pesquisado 
do que no desenvolvimento e na adesão a metodologias particulares. Nas palavras de Robert Chambers, um dos seus principais formuladores, PRA é "a family of approaches and methods to enable rural people to share, enhance, and analyze their knowledge of life and conditions, to plan and to act" (1994a:953).

As técnicas usadas nas atividades do PRA distinguem-se, sobretudo, quanto à ênfase no uso de instrumentos visuais (vários tipos de mapeamentos participativos, matrizes e diagramas), considerados mais idôneos para o "empowerment" dos "mais fracos" e "despossuídos", já que independem da alfabetização ("literacy”) e são praticamente universais (Chambers, 1995:38; para uma crítica a esta formulação, cf. Francis, 2001:81-2). Ao mesmo tempo, os "facilitadores"/pesquisadores são convidados ao exercício contínuo das próprias capacidades de julgamento, em função de maior flexibilidade, criatividade e assunção de responsabilidades: "The most striking insight of the experience of PRA is the primacy of the personal [...] Responsability rests not in written rules, regulations and procedures but in individual judgement" (Chambers, 1994b:1450).

As técnicas do PRA procuram dar lugar a uma "reversão" das relações entre os vários "stakeholders" (Chambers, 1995:35, 39; Stirrat, 2000:39; Francis, 2001:78), na qual as perspectivas privilegiadas sejam as dos atores sobre os quais incide a ação (emic), e não as do observador (ethic). O objetivo é capacitar as pessoas para realizarem as próprias pesquisas e análises, propondo e implementando soluções ajustadas aos problemas evidenciados.

Contudo, nas formulações dos expoentes do PRA, a relação entre "participação" e "empowerment" parece ser postulada de modo simplista, provocando críticas por parte de vários autores. Alguns deles, que representam, digamos, a ponta de lança das críticas à "participação", sublinham o fato de que os efeitos do "empowerment", supostamente provocados na aplicação de formas "genuínas" de "participação", podem revelar-se "tantamount, in Foucauldiam terms, to subjection” (Henkel \& Stirrat, 2001:13). ${ }^{15}$

Veremos agora como essa problemática foi sendo desenvolvida no Banco, prestando particular atenção a um dos seus maiores proponentes e à técnica por ele proposta para atingir o objetivo da "participação" nos projetos financiados pelo Banco: Michael Cernea e sua "engenharia social”.

\section{O Banco Mundial e a "participação"}

No Banco e em outras agências similares - não obstante o uso do termo e as preocupações relativas ao alcance da "participação" dos grupos objeto das intervenções estarem presentes desde os primeiros anos de sua ação (Ranhema, 1992) - foi somente no fim dos anos 80 que o tema começa a ser abordado com certa siste- 
maticidade. Bhatnagar e Williams atribuem à iniciativa de dois vice-presidentes do Banco o início de uma série de atividades que deram vida a vários debates, e a um conspícuo corpus de literatura sobre "participação popular" como instrumento de desenvolvimento (1992:1) produzido no interior da instituição.

Em 1990, com o suporte financeiro da SIDA, agência sueca de desenvolvimento, à qual se juntou posteriormente a alemã GTZ, ${ }^{16}$ foi instituído um "Bank wide learning group" sobre "participação", ${ }^{17}$ com a tarefa principal de analisar 20 projetos financiados pelo Banco que "could be considered participatory" (ibidem), sendo o seu intuito retirar lições positivas e investigar as modificações que o Banco deveria inserir em suas próprias práticas operacionais "to encourage popular participation where appropriate" (ibidem). No "Common Vocabulary Paper" (CVP), redigido pelo Grupo (Bhatnagar \& Williams, 1992:177-182), ${ }^{18}$ define-se "popular participation" como "a process by which people, especially disadvantaged people, influence decisions that affect them" (ibidem:177). ${ }^{19}$

Para o Grupo, o que caracteriza as diferentes formas de "participação" são os “objetivos”, as "unidades", a "intensidade” e os “instrumentos”, o que permite notar certa convergência entre este esquema e aquele de Cohen e Uphoff anteriormente apresentado. Uma leitura mais aprofundada desta classificação revela sobretudo o caráter instrumental - como um meio - que marca a concepção da "participação" dentro do Banco. Os objetivos voltam-se principalmente para as possibilidades que a "participação" oferece no sentido de aumentar a eficácia dos projetos ("beneficiary capacity", "effectiveness", "cost sharing” e "efficency"). ${ }^{20}$ Há, todavia, uma exceção: o primeiro objetivo a ser mencionado, o "empowerment", de fato parece estar mais alinhado com abordagens que consideram a "participação" como um fim em si mesmo. Contudo, as limitações impostas pelo Banco restringem fortemente a possibilidade de que as atividades "participativas" aí empreendidas possam ser pensadas para alcançar este tipo de resultado:

One objective of popular participation may be empowerment - a more equitable sharing of power and a higher level of political awareness and strength for disadvantaged people. If empowerment is the objective, the most important result of a development activity might not be an increase in economic production or incomes but rather the development of people's capacity to initiate actions on their own or influence decisions of more powerful actors. Given the Bank's Articles of Agreement, the Bank does not pursue empowerment as an end in itself" (ibidem:178; ênfase nossa). 
As "unidades" da "participação" são "individuals, households, groups, and communities" (ibidem), e os "níveis" referem-se à abrangência das atividades participativas, "community, provincial and national levels" (ibidem). A "intensidade" pode ser "low-level", como no caso da "information sharing", ou aumentar, como nas atividades de "consultation", "decision making” e "initiating action”. Este último representa, na visão do Banco, o nível máximo de intensidade de "participação" dos beneficiários nos projetos financiados por ele, em que as pessoas chegam a possuir os meios para implementar projetos de desenvolvimento que no futuro não dependam do apoio externo: "initiatives implies a proactive capacity and the confidence to get going on one's own” (ibidem:179).

As técnicas participativas adotadas pelo Banco são principalmente: Beneficiary Assessment (BA), Social Appraisal (SA) e, em menor medida, PRA. O primeiro é um método associado principalmente a Salmen, que o define "an approach to information gathering which assesses the value of an activity as it is perceived by its principal users [...] a systematic enquiry into people's values and behaviour in relation to a planned or ongoing intervention for social and economic change" (Salmen, 1995:1 apud Francis, 2001:73). Social Appraisal consiste em uma técnica desenvolvida especialmente por Michael Cernea para a aplicação das ciências sociais ao trabalho do Banco, cujas propostas apresentamos em seguida. ${ }^{21}$

As principais evidências da adoção das técnicas do PRA por parte de funcionários do Banco podem ser encontradas no Participation Sourcebook (Banco Mundial, 1996), último resultado do trabalho do "Learning Group" do Banco sobre "participação”, que busca mostrar as potencialidades e os possíveis ganhos da incorporação de técnicas participativas nas atividades de desenvolvimento através da apresentação de uma série de experiências amadurecidas no Banco. Contudo, estas experiências são dificilmente aproveitáveis devido à estrutura organizativa que caracteriza o Banco, e o texto que as contém apresenta-se mais como um testemunho dos resultados obtidos através de desempenhos “excepcionais" de indivíduos singulares do que como um manual de métodos e técnicas generalizáveis, o que levou Paul Francis a considerá-lo "a mythical text”, ou seja, uma narração de gestas de indivíduos excepcionais (2001:82-3).

Como acenamos, as ideias, os conceitos e as formulações que caracterizam as atuais discussões sobre "participação" no Banco são sobretudo devedoras da obra de Michael Cernea, o qual propôs, em vários trabalhos (1983, 1991, 1992), uma metodologia para a construção de modalidades participativas de desenvolvimento, baseando-se numa experiência particular: o "Programa Integral para el Desarrollo Rural" (PIDER).

O PIDER foi iniciado em $1973^{22}$ como um vasto programa de investimentos 
rurais para a implementação de pequenos projetos locais em algumas das áreas mais pobres do México. A novidade deste tipo de atividade traduziu-se na necessidade de adotar uma abordagem diferente daquela até então usada em projetos financiados pelo Banco (Cernea, 1983:vii). A perspectiva dos camponeses, os supostos beneficiários diretos dessas intervenções, foi provavelmente, pela primeira vez, considerada relevante para a concepção e a escolha dos vários microprojetos, o que levou ao desenvolvimento de uma metodologia para a inclusão do ponto de vista local na formulação dos vários programas.

As técnicas desenvolvidas ao longo da implementação do projeto são descritas por Cernea como uma metodologia social para a "participação comunitária" em investimentos locais, apresentadas num primeiro trabalho em 1983. O início dessas atividades, em 1974, em sintonia com o novo paradigma desenvolvimentista oficializado nas New Directions, deu-se em função de uma série de considerações sobre a ineficácia dos programas de desenvolvimento rural até então implementados, cujas causas foram atribuídas a pouca consideração das realidades locais nas fases de planejamento, ou seja, na fase inicial de construção dos projetos (Cernea, 1983:10-12).

Pela primeira vez, num projeto financiado pelo Banco, foi organizada uma "task force" de cientistas sociais (além dos economistas), na forma de um "Centro de Investigación para el Desarrollo Rural” (CIDER), com o papel de desenvolver procedimentos para a identificação das necessidades prioritárias e a otimização de investimentos no nível das comunidades. Cernea descreve este exercício como uma atividade de "action research" (1983:13ss; 1992:58), cujos resultados são pensados como importantes sobretudo porque têm "transfer potential to other contexts for which a participatory methodology has to be elaborated" (1983:13). As atividades através das quais esta metodologia foi se formando são descritas por Cernea não somente como "applied social research", mas como "'Social engineering', which could be defined distinctly as using the body of sociological knowledge and of investigation techniques for designing policies, organization structures, and action methodologies to accomplish a definite social purpose" (1983:9). Estas tecnologias foram desenvolvidas a partir de um "social learning process", constituído de movimentos entre pesquisas realizadas no nível do campo e momentos de reflexão teórica (ibidem:19).

$\mathrm{Na}$ opinião de Cernea, as duas posturas típicas das retóricas participativas, denominadas por ele de "paternalista" e "populista", só poderão ser evitadas no momento em que os aspectos sociais e técnico-econômicos sejam considerados conjuntamente no planejamento das intervenções. ${ }^{23}$ Daí a necessidade do trabalho de campo, que permita a coleta das opiniões dos beneficiários, de outros dados 
sobre os mesmos e das características particulares das várias situações locais para serem posteriormente avaliados através de uma "sound analysis [...] because often the proposals emerging from communities contained nothing more than an attractive idea, without back-up technical information and economic justification" (1983:25). O papel dos cientistas sociais revela-se, assim, absolutamente indispensável e determinante no processo de planejamento, sendo eles os únicos capazes de, junto aos técnicos, atuarem na formulação de projetos que consigam mobilizar "latent local resources". Neste sentido, a "participação" é um meio, e não um fim (ibidem:37), através do qual os projetos vêm a ser incorporados "into the life of the community as part of its own achievements" (ibidem).

A metodologia que leva à programação participativa dos planos divide-se em três fases: “a) field assessment, b) preliminary programming, c) final programming” (ibidem:45). A "participação" dos beneficiários nas atividades de planejamento concentra-se especialmente na primeira fase, quando são efetuados os diagnósticos de campo ("field diagnosis"). Estes últimos dividem-se em quatro fases diferentes e têm uma duração média de dois dias em cada localidade. O grupo de experts (no caso em questão, dois ou três técnicos do PIDER e de agências técnicas), antes de efetuar a pesquisa, participa de um seminário no qual são explicados e analisados os seus objetivos, métodos e procedimentos. A primeira atividade consiste em "a trip through the village, to get to know firsthand the social groups and the physical environment in which activities are to be carried out, and to inform the residents of the objectives of the study" (ibidem:47).

Depois, é efetuado um "survey" junto aos informantes selecionados, isto é, as autoridades (neste caso a liderança dos conselhos locais, ou seja, os ejidos, ${ }^{24}$ os delegados das prefeituras etc.), o professor da escola local, os enfermeiros e os médicos (se houver) e a liderança das outras organizações locais (como associações de pais, grupos de créditos e outras). Os dados, assim coletados, são organizados e sistematizados em formulários, cujos conteúdos, ainda que adaptados às condições específicas de cada "região", devem ser padronizados para a comparação das várias pesquisas (ibidem:49). A fase sucessiva consiste na organização de reuniões junto à "comunidade": "there are two ways of holding them: selected issues are discussed with certain groups separately, or the meeting is held in a large, integrated group in which all the information of community interest is discussed" (ibidem). Dependendo da situação, os encontros podem ser organizados com diferentes grupos, ou seja, homens, mulheres e jovens ou, no caso de diferenças notáveis na composição socioeconômica dos grupos, entre "different strata" (cultivadores com mais ou menos terras, com ou sem gado etc.). 
A metodologia ressalta a necessidade de que o grupo de experts faça um esforço para coletar "farmers perspective on each individual investment proposed and should record it on the report form" (ibidem:51), de modo que a "vontade da comunidade" em contribuir para os investimentos necessários à implementação dos vários projetos seja avaliada durante a atividade de diagnóstico da localidade.

A descrição da metodologia aqui efetuada serve sobretudo para ressaltar as diferenças em relação às abordagens do PRA. Como parece evidente, a possibilidade de os beneficiários influenciarem as atividades a serem implementadas depende, em grande medida, da capacidade dos experts na coleta de suas opiniões sobre propostas formuladas externamente, limitando assim a influência sobre a definição das necessidades que os projetos teriam de atender. Claramente, estão aqui em jogo questões de outra natureza: opera-se com uma visão particular do destino das sociedades humanas, ou seja, uma visão de mundo em que a única faculdade concreta de participação na construção do próprio futuro depende da aquisição de capacidades (que lhe são alheias em termos históricos e culturais) para o aproveitamento das possibilidades de inserir-se nos circuitos econômicos e tecnológicos de mercado. ${ }^{25}$

\section{PRA e "Social Engineering": sugestões para uma comparação}

Para ressaltar as principais diferenças e semelhanças entre as duas metodologias acima analisadas pensamos ser útil organizá-las graficamente:

\begin{tabular}{|c|c|c|}
\hline "Participação" & Meio & Fim \\
\hline Unidade básica da ação & Comunidade & Comunidade \\
\hline Foco & Recursos locais & Conhecimentos locais \\
\hline Metodologia & $\begin{array}{l}\text { Contínuo feedback entre coleta } \\
\text { de dados no campo e "sound } \\
\text { analisys"; entrelaçamento das } \\
\text { características sociais e técnico- } \\
\text { econômicas no planejamento } \\
\text { das intervenções; produção de } \\
\text { manuais. }\end{array}$ & $\begin{array}{l}\text { Ênfase na postura do pesquisa- } \\
\text { dor e adoção de instrumentos } \\
\text { "culturalmente neutros" para fa- } \\
\text { cilitar o desenvolvimento das ca- } \\
\text { pacidades internas de análise dos } \\
\text { beneficiários. }\end{array}$ \\
\hline $\begin{array}{c}\text { Resultados a } \\
\text { serem alcançados }\end{array}$ & $\begin{array}{l}\text { Eficácia dos projetos através da } \\
\text { sua adesão à situação local; maior } \\
\text { participação dos beneficiários } \\
\text { nas atividades de desenvolvi- } \\
\text { mento; produção de métodos } \\
\text { replicáveis. }\end{array}$ & $\begin{array}{c}\text { Conscientização; } \\
\text { "empowerment”; } \\
\text { autogestão (self-realiance); } \\
\text { Governance. }\end{array}$ \\
\hline
\end{tabular}


A "engenharia social" quer dar contribuições na construção do "software" dos projetos, ou seja, "the institutional components and the sociocultural parts of these projects" (Cernea, 1983:13). Estes aspectos revestem-se de uma relevância equivalente àquela dos componentes tecnológicos, e revelam a importância da contribuição da "comunidade das ciências sociais" para as atividades de desenvolvimento (ibidem). O objetivo é responder a questões pragmáticas relativas aos modos pelos quais se pode incrementar a "participação" - e quais os custos dessa iniciativa - através da individuação dos fatores contextuais que incidem na probabilidade de sucesso dos projetos (ibidem:14).

Os conhecimentos locais que podem ser aproveitados dizem respeito sobretudo às informações que permitam maximizar as intervenções que as agências optam por implementar. Cernea nos oferece alguns exemplos. Num caso, os conhecimentos locais relativos aos níveis de pluviosidade de uma determinada região em que se construiu uma barragem poderiam ter evitado as falhas no projeto que levaram ao desabamento da mesma, que aconteceu após chuvas que excederam os níveis máximos calculados pelos experts (ibidem:17). Em outro caso, o conselho dos experts, relativo à aquisição de determinadas variedades de gado com o objetivo de cruzá-las com as variedades locais, foi rejeitado com base na experiência de um dos criadores locais que, já tendo realizado essa tentativa, percebera que as características físicas do gado europeu não se adaptavam às condições climáticas locais (Cernea, 1992:29).

A incorporação dos conhecimentos locais nas atividades de planejamento constitui um princípio importante das abordagens participativas em geral (Mosse, 2001:16). Contudo, existem diferenças no valor atribuído ao conhecimento detido pelos beneficiários. Se, de um lado, a "engenharia social" reconhece a utilidade desses conhecimentos para a eficácia dos projetos, prevendo formas que possibilitem aos encarregados da formulação dos programas de desenvolvimento a coleta de tais informações, o foco da metodologia PRA concentra-se nas possibilidades que o "people's knowledge" oferece em desafiar e modificar as estruturas existentes de poder, o papel dos profissionais do desenvolvimento, e as próprias formas dos sistemas de conhecimento em que se baseia a ação desenvolvimentista. Estas ideias pressupõem conceitos particulares relativos ao que seja a "comunidade", o "poder" e o "conhecimento" - e os modos em que são pensadas as relações entre estes - e as possibilidades de "agenciamento" e emancipação dos atores sociais.

Uma análise da forma pela qual o conceito de "comunidade” é empregado na maioria das práticas participativas - e que representa o ponto de convergência das duas abordagens aqui confrontadas - revela algumas das falhas conceituais que norteiam tais atividades. A "comunidade" é usualmente pensada como lugar do con- 
senso, homogêneo e livre de conflitos. ${ }^{26}$ Esta idealização revela um paralelo com noções de "organização social", típicas da antropologia estrutural-funcionalista: sistemas equilibrados de diferentes instituições, concepção hoje reconhecida como mais uma representação/construção do observador do que um fato empírico (Peters, 1996:23; 2000). No entanto, esta representação não parece ter sido completamente abandonada (Mosse, 1997:256ss; Green, 2000:73), e os mesmos pressupostos parecem informar os discursos sobre "participação" e "empowerment" (Woost, 1997:229).

É verdade que, seja no trabalho de Cernea, seja no de Chambers, é reconhecida certa natureza heterogênea das "comunidades". Cernea, ao definir os passos necessários para efetuar aquilo que chama de "community diagnosis", avisa que é necessário levar em conta a existência de diferentes "sets of interests" (1983:38-9). Para este autor, as "mulheres", os "jovens", os "sem-terras", os "camponeses" que se aproveitam de sistemas de irrigação e aqueles que possuem terras não-irrigadas constituem os "subgrupos" que compartilham os mesmos interesses. Chambers, por sua vez, afirma que até estas categorias são insuficientes para mapear a diversidade existente no interior das comunidades:

Nor is it enough to identify just one category, such as women. For there are poor and less poor women, and many other differences between categories of people. The poorest, who live far from the centre, who are weak, or overworked, or used to being excluded, are easily left out of empowering participatory processes (1995:39).

Contudo, a possibilidade de que os pesquisadores consigam dar conta destas diferenças é limitada pela rapidez que caracteriza as suas atividades - o que Chambers chama de "rushing" (ibidem) - resultando daí as dificuldades para mapear as diferentes relações de poder no interior de cada comunidade. ${ }^{27}$ Entretanto, até que seja dividida em subcategorias com interesses diferenciados, a ideia de uma "comunidade" homogênea - enquanto realidade "relevante" sobre a qual devem incidir os esforços de análise e aplicação - continua sendo "a" referência na aplicação das técnicas participativas. Isto faz com que fiquem obscurecidas as forças que agem nos processos de constituição e manutenção desses grupos, as conexões existentes entre diferentes membros e grupos no interior das "comunidades" e os demais circuitos políticos, sociais e econômicos, nos níveis regionais, nacionais e internacionais (Green, 2000:72).

A falha maior das práticas participativas rotineiras parece, então, jazer na construção de uma visão normativa das ações dos atores sociais, tendendo a elimi- 
nar, nas imagens das relações sociais - construídas através das técnicas empregadas - tudo aquilo que não pode ser representado em gráficos e instrumentos similares de descrição da realidade, como ocorrências irregulares, eventos não-rotineiros ou considerados "anormais" (Kothari, 2001:147).

A análise dos modos pelos quais se pensa que os conhecimentos detidos por cada ator social contribuem para a possibilidade de exercício do poder é feita a partir de uma visão racionalista da ação humana, em que todos os atores compartilhariam as mesmas aspirações na aplicação dos próprios conhecimentos sobre o mundo. Assim, a possibilidade que a "engenharia social” oferece aos beneficiários de vociferarem as próprias opiniões sobre os tipos de intervenção que se pretende implementar, constitui, na visão de Cernea, um efetivo "empowerment" dos mesmos, que poderia ser ulteriormente impulsionado através da incorporação dos beneficiários nas atividades de monitoramento das operações e na sua execução (1983:69) - daí a importância de oferecer informações completas à comunidade sobre as intervenções a serem implementadas. Cernea, no entanto, afirma que esta fase de atuação, que constitui uma das características mais importantes na efetividade e na sustentabilidade dos projetos, não foi implementada no PIDER.

$\mathrm{O}$ fato de que os tipos de conhecimentos locais, considerados importantes para um planejamento efetivo das intervenções, sejam filtrados pelos responsáveis das operações de coleta de dados - instruídos para levantar determinados tipos de informações através de técnicas padronizadas - não constitui preocupação central, levando assim a ignorar os modos de produção destes conhecimentos e a não problematizar as condições de comunicação e apreensão dos mesmos.

Outro fator importante a ser sublinhado diz respeito à concepção do conhecimento enquanto um composto de "informações" e práticas operativas quantificáveis, passíveis de codificação e suscetíveis de avaliação por parte dos experts, detentores dos instrumentos para medir a sua utilidade (instrumental) nos projetos de desenvolvimento. Deste modo, as demais formas de conhecimento

which cannot be understood in these terms; which appear to have no instrumental rationale [...] are therefore consigned to the dustbin of "culture" or even "superstition" (and perhaps more frequently are simply excluded from consultants" reports). In other words, indigenous knowledge is only recognized as knowledge when it fits the models of modernity (Stirrat, 2000:39). ${ }^{28}$

No que concerne às técnicas do PRA, o discurso é mais complexo, na medida em que os praticantes destas técnicas alegam a prioridade dos conhecimentos e das visões locais (êmicas) sobre aqueles dos observadores (éticas), postulando uma 
estreita conexão entre o reconhecimento do valor do "local knowledge" e as possibilidades de "empowerment" dos atores locais que o detêm.

Esta afirmação, contudo, não problematiza os modos como tais conhecimentos são produzidos e organizados através das técnicas do PRA, nem a possibilidade de que a própria natureza dos instrumentos adotados contribua para determinar as informações e as imagens dos conhecimentos locais assim obtidos (Kothari, 2001:145ss; Stirrat, 2000).

\section{"Participação" e poder}

Para Maia Green, a construção de uma relação causal entre "participação" e "empowerment" baseia-se no estabelecimento de "a spurius relation between knowledge and agency, in which individual agents are empowered at the level of consciousness, in a vacuum divorced from actual social and political action" (2000:68, ênfase no original). Para a autora, este tipo de raciocínio esconde o fato de que os "pobres" são pensados como incapazes de atingir objetivos de transformação social por si mesmos (como também faz notar Ranhema, 1992), e participam das atividades de desenvolvimento somente através das estruturas institucionais das agências de desenvolvimento destinadas a este fim (ibidem). A possibilidade de que os representantes destas agências consigam contribuir para o "empowerment" dos supostos beneficiários das ações de desenvolvimento vem sendo criticada, sobretudo através da análise das várias formas em que o "poder" é conceitualizado no campo do desenvolvimento.

Nelson e Wright (1995b:8ss) apresentam três modelos conceituais de poder através dos quais se poderia analisar a efetividade das técnicas do PRA, e similares, no sentido de garantir o "empowerment" dos beneficiários. A primeira forma de poder apresentada pelos autores, "power to", postula a possibilidade de que as pessoas possam aumentar o próprio poder (ou seja, o controle sobre as condições que influem em suas vidas) sem necessariamente privar outros de parcelas do mesmo. Isto pode acontecer através do desenvolvimento da confiança nos próprios potenciais, bem como da mudança de atitudes derivada de um confronto entre atores diferentes, por exemplo, um grupo de mulheres que compartilha detalhes do próprio cotidiano e um ator externo que fornece uma diferente "sociological imagination" (Hymes, 1972).

Este confronto permite a ambas as partes questionarem as "realidades" de partida e, assim, modificarem o próprio entendimento, oferecendo instrumentos para tentar mudar o sistema de relações através do qual o poder é exercido. Trata-se de um poder que vem sendo estimulado em cada um através de atividades coletivas, o ato de compartilhar conhecimentos, formas particulares de agir e de se comportar 
ou, em outras abordagens, através do repasse de conhecimentos específicos a grupos e a indivíduos marginalizados (e.g. Page, 1999). Os limites desta visão podem ser identificados, sobretudo, no fato de que nela o poder assume a característica de atributo pessoal, cujo aumento ou cuja diminuição depende da posse de determinados instrumentos (especialmente "cognitivos"). Trata-se da visão do poder como algo substancial, inerente ao indivíduo, que tende a obscurecer o caráter "relacional" das situações que definem a possibilidade de escolha dos vários atores em cada uma delas e o fato de que este mesmo poder multiplica-se e é exercido em rede (cf. Elias, 1991:158ss).

O segundo modelo de poder apresentado, “power over", está mais próximo dos modelos clássicos em que o poder equivale à possibilidade de influir nos processos de decisão política. Neste caso, mais do que corresponder a características pessoais, o poder parece constituir-se em um elemento que existe em quantidade finita, caracterizando uma visão sua como "soma-zero". Este poder é considerado como situado nos centros institucionais e políticos, e exercido por aqueles que o possuem sobre aqueles que não o detêm, sob formas que contribuem para a manutenção dos equilíbrios existentes.

O terceiro tipo de visão do poder é devedor das análises foucaultianas aplicadas por Ferguson (1990) às situações de desenvolvimento. Trata-se de uma visão do poder como algo "descentralizado", que não é possível descrever como substância ou característica pessoal, mas que pode ser representado como um aparato constituído de discursos, instituições, atores e fluxos de eventos.

Todos os três modelos de poder, apesar das diferenças, apresentam problemas similares para aqueles que pretendem, através das técnicas participativas, modificar as relações de poder no mundo do desenvolvimento. Nelson e Wright (1995b:11), referindo-se ao trabalho de Ferguson sobre Leshoto (1990) e aos side-effects das atividades de desenvolvimento por ele evidenciados, apresentam a hipótese de que os programas participativos implementados pelas agências bilaterais e internacionais podem acabar sendo vítimas dos efeitos escondidos do aparato desenvolvimentista, incorporando assim os marginalizados em "even more distant clustering of power undermining their resistance" (ibidem). Do ponto de vista do "power to" e do "power over", os autores levantam dúvidas sobre a possibilidade de que as próprias agências, através do exercício do "poder sobre" ("power over") aqueles subordinados a este mesmo poder, sejam capazes de desencadear processos através dos quais estes últimos consigam aumentar o próprio "poder para" ("power to") assumirem o controle de suas situações.

O nó central da questão da aplicabilidade destas diferentes concepções de poder às situações específicas de desenvolvimento, a nosso ver, consiste no perigo de 
sedimentar a negação da possibilidade daqueles considerados marginalizados ou mais "pobres" de exercerem formas eficientes de pressão sobre as situações de constrangimento que limitam o acesso a recursos e a processos de decisão política que afetam suas vidas. Trata-se, em suma, do risco de reproduzir determinadas visões de relações de poder como "naturais", através da negação da possibilidade de "agenciamento" autônomo que tende a mostrar os "objetos" do desenvolvimento como incapazes, se não através da intervenção externa, de exercitar qualquer forma de poder sobre as ações dos "mais poderosos" (Rahnema, 1992).

A tentativa de fortalecer as instituições organizacionais de grupos etnicamente diferenciados, que aos olhos das agências internacionais e bilaterais de desenvolvimento representam os marginalizados, baseia-se exatamente neste tipo de raciocínio, cuja validade, achamos, pode ser posta em dúvida através da consideração de vários casos etnográficos [e.g. Ferraz, 1983, 1998; Almeida, 1991, 2001; Oliveira \& Almeida, 1998; Fisher, 1994]. Para remarcar a influência do trabalho de Michael Cernea relativamente ao desenvolvimento desta visão particular da relação entre o "social" e os processos de desenvolvimento, que se encontra na base das atuais formulações e práticas de um amplo conjunto de atores (sobretudo Agências, Instituições e ONGs que têm o Banco como uma das principais referências), lançamos agora um último olhar sobre a "engenharia social" e a metáfora do "software".

Cernea lamenta que uma das fraquezas do PIDER tenha sido a incapacidade de

establishing and encouraging the social organization necessary for the peasants to take over and operate successfully the productive assets. Absorption of new technologies, or new production means, requires new and adequate social organization of the farmer, but PIDER I did not provide the required social engineering assistance for this part of the development process" (1983:84; ênfase no original).

O autor põe a ênfase sobre a necessidade de agir não apenas no nível das atividades econômicas e das tecnologias de produção, mas sobretudo sobre as formas de organização interna dos grupos-“alvo”. Podemos ver expressa a ideia de que as organizações locais e as "estruturas sociais" precisam ser modificadas, fortalecidas e adaptadas às condições de produção necessárias a maiores níveis de desenvolvimento. De fato, a sentida necessidade de modificar os modos em que as realidades locais se relacionam com as instâncias administrativas regionais e nacionais representa um dos eixos centrais seja da "engenharia social" de Cernea, seja das atuais linhas de ação perseguidas pelo Banco. O que parece resultar da leitura do trabalho de Cernea é a sobreposição de significados entre "estrutura social", "organização formal” e "formas institucionais," sobreposição (ou “confusão”) que caracteriza, a nosso ver, 
os modelos atuais de intervenção pensados pelo Banco junto às minorias étnicas (Salviani, 2002).

\section{Conclusões. Os antropólogos diante das técnicas participativas: perspectivas do momento e do futuro}

Parece-nos que uma das lições que podemos tirar de nossa apresentação deste horizonte de pensamento acerca das técnicas participativas é aquela relativa à emigração de conceitos, práticas e modelos teóricos referentes à natureza da "sociedade”, provenientes da antropologia, para o campo do desenvolvimento.

Boa parte da historia da antropologia é marcada pelo habitus dos antropólogos de isolar "sociedades" às quais corresponderiam "culturas" particulares. Este modus operandi tem sido alvo das criticas contundentes de autores como Frederick Barth (1966, 1969), Benedict Anderson (1983) e Adam Kuper (1992), entre outros. Para estes autores, a escolha deste tipo de recorte no estudo dos grupos sociais, tinha a ver menos com a natureza dos fenômenos sociais e mais com a história das relações de poder no meio da qual a disciplina nasceu e se desenvolveu. Apesar de serem muitas e relevantes as discussões e as críticas que norteiam os avanços da disciplina antropológica em relação a esse recorte do social, suas repercussões não parecem ter chegado a influir sobre as representações internas ao campo do desenvolvimento, como mostramos a tratar do conceito de "comunidade". ${ }^{29}$ Daí a necessidade de nos alertarmos criticamente sobre a natureza do fenômeno do desenvolvimento em geral, e sobre o papel da antropologia e dos antropólogos no interior deste campo, e concentrarmos nossa atenção sobre as relações entre antropologia e desenvolvimento. O que nos leva nesta direção é a convicção de que, ao invés de aceitarmos colaborar nas práticas de “desenvolvimento", perguntando quais mudanças operar no nosso modo de produção de conhecimento para que este seja mais acessível aos responsáveis pela definição dos termos da implementação (como fazem, por exemplo, Hinshaw, 1980 e Scudder, 1999), este mesmo modo de produção de conhecimento teria de ser questionado. No mesmo sentido em que, para Pels, a antropologia do colonialismo teria que ser antes de tudo uma antropologia da antropologia (1997:164), a antropologia do desenvolvimento teria que ter, como um dos seus principais objetivos, o questionamento do papel da antropologia em determinar o caráter inquestionável que o "desenvolvimento" tem assumido como prática e objetivo histórico.

Especialmente hoje, pelo fato de os instrumentos de análise antropológica serem considerados indispensáveis para atuar com sucesso em muitas áreas do campo do desenvolvimento, a participação dos antropólogos deve ser informada pela consciência das estruturas conceituais e de poder que o norteiam. Cada situação 
pode reservar mais ou menos espaço de manobra para que os conceitos de "participação" e "empowerment" passem a desempenhar um papel político em vez de ideológico, e nos cabe nos responsabilizarmo pelas consequências de nossas colaborações (cf. Stirrat, 2000:41). Se, como mostra Ferguson (1990), a indústria do desenvolvimento aproveita-se dos conhecimentos das ciências sociais segundo suas próprias exigências, então nos cabe fazer com que os conhecimentos que produzimos para este fim não deixem espaço para um uso instrumental dos mesmos, que separe as práticas dos contextos político-sociais em que são implementadas.

\section{Notas}

1. O termo "campo" é aqui usado para descrever, de modo "impressionista", o conjunto de elementos com os quais pensamos ser necessário lidar para elaborar uma análise antropológica do fenômeno do "desenvolvimento", sem a pretensão de se fazer referência a uma das teorias específicas dos campos, ou ainda esboçar o conjunto de atores-ideias-práticas-discursos que pertençam exclusivamente (ou seja, aqueles, e não outros) ao "campo do desenvolvimento" (uma proposta deste tipo de construção do "campo" encontramos, por exemplo, em Max Gluckman, no seu famoso ensaio sobre Zululandia, 1986). A questão dos limites do "campo do desenvolvimento" deveria mais que constituir um dos pressupostos da pesquisa fazer parte dos objetos da mesma. Ao concordarmos com a formulação de um dos autores que mais têm feito uso dela e, assim, tentado definir operacionalmente o conceito de "campo" para sua aplicação nas ciências sociais, nos damos conta da impossibilidade de definir a priori o conjunto de atores-práticas-discursos que a este campo pertenceriam: "o limite de um campo é o limite de seus efeitos ou, em outro sentido, um agente ou uma instituição faz parte de um campo na medida em que nele sofre efeitos ou que nele os produz" (Bourdieu, 1989:31).

2. Esta mudança nas políticas desenvolvimentistas, denominada "New Directions" (Horowitz \& Painter, 1986:2), revelou-se extremamente importante na medida em que influenciou processos internos à disciplina antropológica e intensificou as contribuições de antropólogos para as atividades de desenvolvimento (Hoben, 1982:356-7). Autores como Lucy Mair (1984:10-14), Cernea (1991:3ss) e Tayer Scudder (1999:359-60), entre outros, descrevem os antropólogos como os especialistas mais indicados - pelo conhecimento profundo das situações locais e características culturais - a oferecer contribuições valiosas na compreensão de aspectos até então negligenciados, cuja consideração é necessária para a melhoria da qualidade das intervenções.

3. O objetivo de Finnemore, contudo, consiste em demonstrar que as formas dos programas, pensadas como corretas para alcançar os novos objetivos, dependem estreitamente das características organizacionais do Banco: "The kind of poverty-oriented development programs eventually pushed by the Bank looked the way they did, not because they were obvi- 
ously or objectively best-suited to the task of poverty alleviation but because they met the organizational needs of the Bank" (Finnemore, 1997:208).

4. A bibliografia dos trabalhos de antropólogos e sociólogos publicados pelo Banco entre 1975 e 1993 (Cernea, 1994) mostra o aumento exponencial dessas colaborações ao longo dos anos 80 .

5. As primeiras propostas relativas à necessidade/utilidade de levar a efeito os conhecimentos adquiridos nas ciências sociais para a formulação de políticas de administração de populações e territórios, ou seja, da relevância prática dos mesmos pela "engenharia social" (ver nota 6), vêm de Karl Pearson (1921) e Malinowsky (1929). Relativamente à história e às características da Antropologia Aplicada em face de outras disciplinas e práticas de "mudança social induzida,” o texto homônimo de Bastide (1971) é, ainda hoje, referência fundamental. Para um mapeamento das discussões contemporâneas das relações e entre ações de desenvolvimento e a antropologia, sugerimos a leitura dos artigos publicados por Robert A. Hackemberg em Human Organization, a partir de 1999, no editorial temático: "Advancing Applied Anthropology" (e.g. 1999a, 1999b, 1999c). Para algumas propostas de revisão das práticas antropológicas para sua inserção no campo das políticas de desenvolvimento, ver, entre outros, Lucy Mair, 1971; Robert Chambers, 1997; Paul Sillitoe, 1998.

6. Vários autores apontam a estreita ligação entre o surgimento de ideias relativas à possibilidade/necessidade de canalizar os processos de mudança social de amplos setores populacionais, ou seja, de praticar uma "engenharia social” em vasta escala, e os processos de construção do "Estado-Nação" (e.g. Scott 1998:91-2). Os processos de “coletivização" em que se veem empenhados os Estados Nacionais (na Europa e nos Estados Unidos) na época moderna (cf. de Swaam, 1988) são propedêuticos à criação do objeto "sociedade", cujas características concorrem para moldar em função das próprias exigências administrativas (cf. Burchell, Gordon \& Miller, 1991). Relativamente à inserção da antropologia como instrumento apto à definição das intervenções, já em 1948 Alfonso Villa Rojas podia afirmar que "Pasando por alto las múltiples controversias, ensayos y proyectos realizados desde entonce [1920, NDA] en el campo de la Antropologia Aplicada, puede decirse que, en la actualidad, esta disciplina ha sentado a sus cartas de validez como auxiliar poderoso en todo asunto de ingenieria social” (1948:303).

7. Michael Cernea, formado em sociologia na universidade de Bucarest, Romênia, possui Ph.D. em sociologia e filosofia social. Entrou no Banco em 1974 como primeiro Rural Sociologist, e foi promovido em seguida Senior Rural Sociologist. Depois de um breve período de ausência (1979-80), voltou a trabalhar no Banco Mundial como Senior Sociologist e, em 1982, foi promovido Sociology Advisor. Em 1990 foi apontado Senior Adviser for Sociology and Social Policy, função que ocupou até 1997. Além de atividades de docência em várias universidades na Europa e nos Estados Unidos (entre outras, em Harvard), foi apontado Professor Honorário para Estudos Sociais e de Reassentamento na Universidade de Hohai, Nanjing, China. Membro 
da Academia das Ciências na Romênia desde 1991, recebeu o Solon T. Kimball Award for Public Policy and Applied Anthropology, da American Anthropological Association, e o Bronislow Malinowski Prize, da Society for Applied Anthropology. Robert Chambers é Fellow of the Institute of Development Studies da Universidade de Sussex, Inglaterra, onde continua trabalhando sobre Participação no Desenvolvimento. Ocupou-se extensivamente de desenvolvimento rural na África saariana e na Ásia meridional. AAEAFellow pela University of Maryland, em 1999 ganhou o AAEA Publication of Enduring Quality Award.

8. Não pudemos aprofundar neste ensaio a questão - a nosso ver de grande importância (cf. as conclusões) - das relações entre antropologia e desenvolvimento (sobretudo "participativo”). Ver também Salviani, 1997, 2002.

9. Apesar dos enfoques diferentes, as análises dos vários autores que se interessam pelas raízes históricas do desenvolvimento enquanto ideologia e prática administrativa apresentam certa complementaridade. Rist mostra como as ideias de São Agostinho contribuíram na estruturação do pensamento positivista, por oferecerem os argumentos para uma visão linear da história e a consequente possibilidade de articular uma ideologia desenvolvimentista (1999:31-4). Cowen e Shenton (1995:31-5), entre outros (e.g. Berman, 1989:78ss; Rich, 1994:214-20), veem nascer a empresa desenvolvimentista, na sua acepção "moderna", no seio da problemática situação europeia dos anos 1830-40, através da obra de personagens como os saint-simonianos, List e Comte. Outros sublinham as conexões entre os aparatos de dominação colonial e as técnicas de desenvolvimento (Cooper \& Packard, 1997; Fisher, 1997; Mosse, 1997; Stirrat, 2000). Outros, ainda, preocupam-se com os aspectos modernos do fenômeno, e restringem a atenção aos últimos 50 anos, propondo que o início do atual "discurso do desenvolvimento" pode ser individualizado no discurso à nação norte-americana proferido por Truman em janeiro de 1949 (Esteva, 1992:6; Escobar, 1995:24-34).

10. Metodologicamente, o ciclo da Pesquisa-Ação é bastante simples e substancialmente válido para todas as suas elaborações. Ele compreende: 1. Identificação dos problemas a resolver, dos fatores causais existentes, das limitações ambientais presentes e das habilidades profissionais passíveis de serem aproveitadas; 2. Formulação das hipóteses de mudança e dos planos de implementação; 3. Aplicação das hipóteses nos contextos-objetos dos planos formulados; 4. Avaliação das mudanças e implementação dos métodos aplicados; 5 . Aprofundamento, institucionalização e difusão capilar das aplicações que foram avaliadas como bemsucedidas ou positivas (Walton \& Gaffney, 1991).

11. As principais "linhas" metodológicas que foram desenvolvidas podem se resumidas em:

- pesquisa ação (action research)

- pesquisa participativa (participatory research)

- pesquisa ação participativa (participatory action research)

- pesquisa ação participada (participated action research) 
- ciência-ação (action science)

- sociologia da ação (sociologie de l'action).

12. Nelson e Wright (1995a) operam um confronto das duas técnicas - pesquisa participativa e observação participante - evidenciando as diferenças entre as duas e os possíveis ganhos que resultariam da união de algumas das características que as distinguem.

13. Chambers (1995:36) oferece um elenco de 29 tipos de abordagem participativa que tomam forma a partir dos anos 70, assinalando o caráter não-exaustivo do mesmo.

14. O termo "empowerment" e os significados a ele atribuídos mereceriam um tratamento aprofundado que não podemos desenvolver nesta sede. O termo vem do século 19, ganhando atribuições específicas no seu uso moderno e dando lugar a convergências de sentido quando da sua utilização em campos entre eles bastante diferentes, como aqueles relativos à teoria da gestão de empresa, o dos discursos e das políticas de modernização e democratização do Estado nos anos 80, e o dos movimentos sociais esquerdistas, "verdes” e feministas. Tais convergências e difusão revelam certa "ambiguidade funcional” no seu emprego (James, 1999:14-20. Ver também Ranhema, 1992; Gledhill, 1994). Ao longo dos anos 90, “empowerment” adquiriu um emprego difundido no campo do desenvolvimento, como se pode perceber ao olhar a produção bibliográfica do mesmo período (Cheater, 1999:1). Como nota Angela Cheater, os problemas de definição de "empowerment" têm a ver sobretudo com diferentes interpretações do conceito de "poder", cuja problematização atual se deve principalmente ao trabalho de Foucault (e.g. 1998) e à crítica pós-moderna. Na última parte deste ensaio, apresentaremos brevemente as principais concepções de poder que parecem guiar o uso do termo "empowerment” no campo do desenvolvimento. Para uma série de contribuições críticas de cunho antropológico, ver, entre outros: Argyris, 1998; Cheater, 1999; Wendt, 2001; Botchway, 2001; Henkel \& Stirrat, 2001.

15. Ver também Stirrat (2000) e Green (2000:68).

16. A Swedish International Agency for Development (SIDA) destina aproximadamente um terço dos recursos próprios às agências multilaterais das Nações Unidas ao Grupo Banco Mundial, a outros bancos regionais de desenvolvimento e à União Europeia. Os seus principais objetivos são o combate à pobreza, à degradação ambiental e a resolução de situações de conflitos, para criar condições que conduzam à mudança e ao desenvolvimento sustentável ambiental, social e econômico. A Deutsche Gesellschaft für Technische Zusammenarbeit (GTZ), fundada em 1975, depende principalmente do Ministério Alemão para a Cooperação Econômica e o Desenvolvimento (BMZ), que a vem encarregando de implementar a Cooperação Técnica (TC) através da comunicação de conhecimentos relativos às áreas da tecnologia, da economia e das formas organizativas.

17. O Grupo, foi composto por um "Core Team" de 15 funcionários do Banco; desde 1991 passou a contar com a colaboração de 20 “Task Managers” responsáveis por projetos "that appear[ed] to be participatory", e de 10 "Bank advisers" que assistem aos demais 
sobres questões específicas (Bathnagar \& Williams, 1992:2. Para ter acesso à lista completa dos componentes do Grupo em 1992, ver o anexo 1:175-6). Em 1994, o Grupo contava com 55 membros, valendo-se também da colaboração de seis antigos componentes do Grupo que não trabalhavam mais no Banco (Banco Mundial, 1994, anexo 1).

18. O CVP foi desenvolvido pelo "Core Team” do Grupo para explicitar definições e conceitos sobre "participação" que orientariam os trabalhos do Grupo (Bathnagar \& Williams, 1992:2).

19. O termo "popular" pretende incluir todos os indivíduos "who are disadvantaged in terms of wealth, education, ethnic group, or gender" (ibidem).

20. Em suma, são medidas de eficácia econômica.

21. Baseando-se em vários documentos, Francis calcula a presença de BA, de 1983 a 1998, em 110 projetos do Banco e, a partir de 1994, um total de 125 SA está concluído ou em via de formulação. A concentração de tais práticas nos últimos cinco anos atesta a crescente "popularidade" destas metodologias (2001:84).

22. O processo de atividades ao qual nos referimos como PIDER é constituído, na realidade, por diferentes programas sucessivos, chamados de PIDER I, II, e III.

23. "The simultaneity in preparing both types of "instruments" - social and technicoeconomic - was in fact an adequate response to two fallacies often present in the arguments for or against participation - the "populist" fallacy and the "paternalistic" fallacy. As has been correctly argued, the populist fallacy which contends that the rural majority always "knows better" than the technical personnel and has sufficient skills is as erroneus as the paternalistic fallacy which pretends that the bureaucracy knows best and can do alone all that is needed for development (Uphoff \& Esman, 1974 apud Cernea, 1992:37-8).

24. Instâncias administrativas das "comunidades camponesas" características do agro mexicano.

25. Este, nos parece, é o tipo de visão do futuro definida por Ulf Hannerz como "scenario of global homogeneization of culture" (1993:108).

26. Trata-se, em outras palavras, de formulações que concorrem para a construção do "Outro" (ou, querendo, de um "Nós") como [socialmente?] diferente, e que remetem, entre outras, às ideias de Ferdinand Tonnies sobre Gemeinshaft e Gesellshaft (1957), e àquelas de Talcott Parson (e.g. 1965:30-79) sobre a natureza dos sistemas sociais.

27. Praticamente todos os autores que tratam do argumento lamentam-se dos tempos demasiadamente curtos à disposição dos cientistas sociais encarregados de desenvolver as análises sociais relativas a projetos de desenvolvimento.

28. A "mercantilização" dos conhecimentos, como mostra Lyla Mehta (2001), com a relativa equiparação de "informação" e "conhecimento" e a escolha do modelo Billy Gates/Microsoft como exemplos de perspectiva a seguir, representa a última novidade em termo de políticas do Banco.

29. As críticas relativas aos limites da utilidade do uso do conceito de "sociedade" em 
antropologia, formuladas por Barth (1992), podem ser aproveitadas aqui para questionar a "homogeneidade" atribuída, segundo o pensamento desenvolvimentista (e não só), aos grupos indígenas (Salviani, 2002). Segundo Barth, as maiores dificuldades que encontramos ao tentar definir a natureza de "sociedades" dependem, entre outras, de serem consideradas como "aggregate of social relations" (1992:19), ou como "aggregate of institutions of a population” (ibidem; sobre o caráter convencional do termo, ver Gupta \& Ferguson, 1997). Estas considerações têm consequências no modo como tentamos representar as comunidades locais e, sobretudo, impedem ao observador a consideração de todos aqueles eventos que não parecem se encaixar nesta representação: "I would argue [...] that the anthropological construct of the local community is itself a stifling, pervasive artifact of the traditional anthropological fiction of society, which has often perverted our understanding and representation of the realities of life in small communities and prevented the anthropological fieldworker from noticing, exploring, depicting, and drawing the required conclusions from evidence which is pervasively accessible” (Barth, 1992:29). 


\section{Referências bibliográficas}

ALMEIDA, R.F.T. de. 1991. O projeto Kaiowa-Ñandeva: uma experiência de etnodesenvolvimento junto aos Guarani-Kaiowa e Guarani-Ñandeva contemporâneos do Mato Grosso do Sul. Dissertação de Mestrado em Antropologia Social, PPGAS/MN/ UFRJ.

. 2001. Do desenvolvimento comunitário à mobilização política.

O Projeto Kaiowa-Ñandeva como experiência antropológica. Rio de Janeiro: Contra Capa.

ANDERSON, B. 1983. Immagined Communities. London: Verso.

Argyris, C. 1998. "Empowerment: the emperor's new clothes". Harvard Business Review, 77(3).

BANCO MUNDIAL. 1994. El Banco Mundial y la Participacion. "Operation Policy Department”. Washington, D.C.: The World Bank.

. 1996. The World Bank Participation Sourcebook. Washington, D.C., Environmentally Sustainable Development (ESD): The World Bank.

BARTH, F. 1966. Models of Social Organization. Glasgow: The University Press.

BASTIDE, Roger. 1971. Anthropologie Appliquèe. Paris: Petite Bibliothèque Payot.

. 1992. "Towards greater naturalism in conceptualizing societies". In: KUPER, A. Conceptualizing Society. London and New York: Routledge.

BHATNAGAR, B. \& WILliamS, A. C. (eds.). 1992. Participatory Development and the World Bank. Discussion Papers n. 183. Washington, D.C.: The World Bank.

BERMAN, M. 1989. Tudo o que é sólido se dissolve no ar. A aventura da Modernidade. Rio de Janeiro: Edições 70. 
BOTCHWAY, K. 2001. "Paradox of Empowerment: Reflections on a Case Study from Northern Ghana”. World Development, 29(1).

BOURDIEU, P. 1989. O poder simbólico. Rio de Janeiro: Editora Bertrand Brasil.

BROWN, L. D. \& TANDON, R. (eds.). 1969. Ethnics Groups and Boundaries: The Social Organization of Cultural Difference. London: G. Hallen \& UNWIN.

BURCHELl, G.; GORDON, C. \& MILlER, P. (eds.). 1991. The Foucault Effect. Studies in governamentality. Chicago: Univesrity of Chicago Press.

CERNEA, M. 1983. "A Social Methodology for Community Participation in Local Investments: The Experience of Mexico’s Pider Program”. Working Paper, n. 598. Washington, D.C. : The World Bank.

. 1991. "Using Knowledge from Social Science in Development Projects". Discussion Papers, n. 114. Washington D.C.: The World Bank.

. 1992. "The Building Blocks of Participation: Testing Bottom-Up Planning”. Discussion Papers, n. 166. Washington D.C.: The World Bank.

. 1994. "Sociology, Anthropology, and Development. An Annotated Bibliography of World Bank Publications (1975-1993)”. Environmentally Sustainable Development Studies and Monographs, n. 3. Washington D.C.: The World Bank.

CHAMBERS, R. 1994a. "The Origins and Practice of Participatory Rural Appraisal”. World Developement, 22(7).

. 1994b. "Participatory Rural Appraisal (PRA): Challenges, Potentials and Paradigm”. World Development, 22(10).

.1995. "Paradigm shifts and the practice of participatory research and development”. In: NELSON, N. \& WRIGHT, S. (eds.). Power and Participatory Development. London: Intermediate Technology Publications. 
. 1997. "Responsible well being - A Personal Agenda for Development”. World Development, 25(11), Editorial.

CHEATER, A. (ed.). 1999. The Anthopology of Power. London: Routledge.

COHEN, J.M. \& UPHOFF, N.T. 1980. “Participation's place in rural development: Seeking clarity through specificity". World Development, 8(3).

COOKE, B. \& KOTHARI, U. (eds.). 2001. Participation, The New Tyranny? London: Zed Books.

COOPER, F. \& PACKARD, R. (eds.). 1997. International Development and the Social Science. Berkeley-Los Angeles-London: University of California Press.

COWEN, M. \& SHENTON, R. 1995. “The Invention of Development”. In: CRUSH, J. (ed.). Power of Development. London-New York: Routledge.

DESHLER, D. \& SOCK, D. 1985. "Community Participation: A concept review of the International Literature. Paper prepared for the International League for Social Commitment. Adult Education:22-26, Ljungskile, Sweden, July.

ELIAS, N. 1991 [1970]. Qu'est-ce que la sociologie? Paris: Editions de l'Aube.

ESCOBAR, A. 1995. Encountering Development: the Making and the Unmaking of the ThirdWorld. Princeton: Princeton University Press.

ESTEVA, Gustavo. 1993. "Development”. In: SACHS, W. (ed.). The Develpment Dictionary: A Guide to Kowledge and Power. London and New York: Witwatersrand University Press, Zed Books.

EYBEN, R. 2000. "Development and Anthropology: A View from Inside the Agency". Critique of Anthropology 20(1).

EYBEN, R. \& LADBURY, S. 1995. "Popular participation in aid-assisted projects: why more in theory than practice?". In: NELSON, N. \& WRIGHT, S. (eds.). Power and Participatory Development. London: Intermediate Technology Publications. 
FALS BORDA, O. 1981.“The challenge of action research”. Development, 1.

FERGUSON, J. 1990. The Anti-Politics Machine: "Develpment", Depoliticization, and bureaucratic Power in Lesotho. Cambridge-New York: Cambridge University Press.

FERRAZ, I. 1983. Os Parkatêjê das Matas do Tocantins: A Epopeia de um Líder Timbira. Dissertação de Mestrado, Departamento de Ciências Sociais da Faculdade de Filosofia, Letra e Ciências Humanas da Universidade de São Paulo.

1998. De “Gaviões” à “Comunidade Parkatêjêe”: Uma Reflexão sobre Processos de Reorganização Social”. Tese de Doutorado, PPGAS/MN/UFRJ, Rio de Janeiro.

FINNEMORE, M. 1997. "Redefining Development at the World Bank”. In: Cooper, F. \& Packard, R. (eds.). International Development and the Social Science. Berkeley-Los Angeles-London: University of California Press.

FISHER, W.F. 1994. "Megadevelopment, Environmentalism, and Resistance: The Institutional Context of Kayapó Indigenous Politics in Central Brazil”. Human Organization, 53(3).

. 1997. "Doing Good?The Politics and Antipolitics of NGO Practices". Annual Review of Anthropology, 26.

FOUCAULT, M. 1971. “Sobre a Arqueologia das Ciências. Resposta ao Círculo Epistemológico". In et al. Estruturalismo e Teoria da Linguagem. Petrópolis: Vozes.

1998. Microfísica do Poder. Rio de Janeiro: Graal.

FRANCIS, P. 2001. "Participatory Development at the World Bank: The Primacy of Process”. In: COOKE, B. \& KOTHARI, U. (eds.). Participation, The New Tyranny. London: Zed Books.

FRANCIS. P. \& JACOBS, S. 1999. "Institutionalizing Social Analysis at the World Bank”. Environmental Impact Assessment Review, 19:341-357. 
FREIRE, P. 1970. Pedagogia del Oprimido. Montevideo: Tierra Nuova.

GLEDHILL, J. 1994. Power and Its Disguises. Anthropological Perspectives on Politics. London and Boulder: Pluto Press.

GLUCKMAN, Max. 1986. "Análise de uma situação social na Zululândia Moderna”. In: FEDMAN-BIANCO, Bela (org.). Antropologia das Sociedades contemporâneas - Métodos. São Paulo: Global Universitária-Antropologia.

GREEN, M. 2000. "Participatory Development and the Appropriation of Agency in Southern Tanzania". Critique of Anthropology, 20(1).

GUPTA, Akhil \& FERGUSON, James. 1997. Culture, Power, Place: Explorations in Critical Anthropology. Durham, N.C.: Duke University Press.

HACKEMBERG, Robert A. 1999a. "Strategies and Game Plans". Human Organization, 58(1).

. 1999b. "Globalization: Touchstone Policy Concept or Sucked Orange?”. Human Organization, 58(2).

. 1999c. "Victim of Globalization: Is Economics the Instrument Needed to Provide Them a Share of the Wealth?”. Human Organization, 58(4).

HANNERZ, U. 1993. "Scenarios for Peripheral Cultures". In: KING, A.D. (ed.). Culture globalization and the world-system. London-New York: Macmillan-State University of New York.

HENKEL, H. \& STIRRAT, R. 2001. "Participation as Spiritual Duty; Empowerment as Secular Subjection”. In: COOKE, B. \& KOTHARI, U. (eds.). Participation, The New Tyranny. London: Zed Books.

HILDIARD, N.; HEGDE, P.; WOLVEKAMP, P. \& REDDY S. 2001. "Pluralism, Participation and Power: Joint Forest Management in India”. In: COOKE, B. \& KOTHARI, U. (eds.). Participation, The New Tyranny. London: Zed Books. 
HINSHAW, R.E. 1980. "Anthropology, administration, and Public Policy”. Annual Review of Anthropology, 9.

HOBEN, A. 1982. "Anthropologists and Develoment". Annual Review of Anthropology, 11.

HOROWITZ, M. \& PAINTER, T. M. 1986. Anthropology and Rural Development in West Africa. Boulder and London: Westview Press.

HYMES, D. 1972. "The use of anthropology: critical, political, personal”. In: (ed.). Reinventing Anthropology. New York: Random House.

JAMES, W. 1999. "Empowering ambiguities”. In: Cheater, A. (ed.). The Anthopology of Power. London: Routledge.

KAUFMANN, G. 1997. "Watching the developers: a partial ethnography". In: GRILLO, R.D. \& STIRRAT, L.R. (eds.). Discourses of Development. Anthropological Perspectives. Oxford-New York: Berg.

KOTHARY, U. 2001. "Power, Knowledge and Social Control in Participatory Development”. In: Cooke, B. \& Kothari, U. (eds.). Participation: The New Tyranny. London: Zed Books.

KUPER, A. 1992. Conceptualizing Society. London and New York: Routledge.

LEWIN, K. 1946. "Action research and minority problems”. Journal of Social Issues, n.2.

MAIR, L. 1971. Anthropology and Social Change. London: W. Clowes \& Sons. 1984. Anthropology and Development. London: McMillan Press.

MALINOWSKI, B. 1929. "Practical Anthropology”. Africa, 2(1).

MEHTA, L. 2001. “The World Bank and its Emerging Knowledge Empire”. Human Organization, 60(2). 
MICHENER, V. 1998. "The Participatory Approach: Contradiction and Co-option in Burkina Faso". World Development, 26(12).

MOSSE, D. 1997. "The Ideology and Politics of Community Participation: Tank Irrigation Development in Colonial and Contemporary Tamil Nadu”. In: GRILLO, R.D. \& STIRRAT, L.R. (eds.). Discourses of Development. Anthropological Perspectives. Oxford-New York: Berg.

2001. “Peple’s Knowledge', Participation and Patronage: Operations and Representations in Rural Development”. In: COOKE, B. \& KOTHARI, U. (eds.). Participation, The New Tyranny. London: Zed Books.

NELSON, N. \& WRIGHT, S. 1995. (eds.). Power and Participatory Development. London: Intermediate Technology Publications.

. 1995a. "Participatory research and participant observation: two incompatible approaches". In: (eds.). Power and Participatory Development. London: Intermediate Technology Publications.

. 1995b. "Participation and power". In: (eds.). Power and Participatory Development. London: Intermediate Technology Publications.

OLIVEIRA, J.P. DE \& ALMEIDA, A.W.B. de. 1998. "Demarcação e reafirmação étnica: um ensaio sobre a FUNAI”. In: OLIVEIRA, J.P. (org.). Indigenismo e territorialização. Poderes, rotinas e saberes coloniais no Brasil Contemporâneo. Rio de Janeiro: Contra Capa.

PAGE, N. 1999. "Empowerment: What Is It?". PEP Program, University of Connecticut. Em: http: //joe.org/joe/1999october/comm1.html

PARSON, T.; SHILS, E.; NAEGELE, K.P. \& PITTS, J. (eds.). 1965. Theories of Society. Fundations of Modern Sociological Theory. New York \& London: The Free Press \& Collier Macillan.

PEARSON, K. 1921. “The Science of Man: Its Needs and Its Prospects”. Report of the Smithsonian Institute, Washington

PELS, P. 1997. "The Anthropology of Colonialism: Culture, History, and the Emergence of Western Governmentality”. Annual Review of Anthropology, 26. 
PETERS, P. 1996. “'Who's Local Here?' The Politics of Participation in Development”. Cultural Survival Quarterly, 3. 2000 (ed.). Development Encounters. Harvard: Harvard University Press.

RAHNEMA, M. 1992. “Participation”. In: Sachs, W. (ed.). The Develpment Dictionary: $A$ Guide to Kowledge and Power. London and New York: Witwatersrand University Press, Zed Books.

RICH, Bruce. 1994. Mortgaging the Earth. TheWorld Bank, Environmental Impoverishment, and the Crisis of Development. Boston: Bacon Press.

RIST, G. 1999 [1996]. The History of Development. London-New York-Cape town: Zed Books-UCT Press.

SACHS, W. (ed.). 1992. The Develpment Dictionary: A Guide to Knowledge and Power. London and New York: Witwatersrand University Press, Zed Books.

SALMEN, L.F. 1995. "Beneficiary Assessment: An Approach Described". World Bank Environmental Department Papers, Social Assessment Series 23.

SAlVIANI, R. 1997. Un Progetto di Sviluppo su basi Antropologiche: il Progetto Kaiowañandeva. Dissertação de Mestrado em Antropologia Social, Università degli Studi di Roma "La Sapienza".

. 2002. "As Propostas para Participação dos Povos Indígenas no Brasil em Projetos de Desenvolvimento Geridos pelo Banco Mundial: um Ensaio de Análise Crítica”. Dissertação de Mestrado, Museu Nacional, PPGAS/UFRJ.

SCOTT, J.C. 1998. Seeing Like a State. How Certain Schemes to Improve the Human Condition Have Failed. New Haven \& London: Yale University Press

SCUDDER, T. 1999. "The Emerging Global Crisis and Development Anthropology: Can We Have na Impact?” Human Organization, 58(4).

SILLITOE, P. 1998. "The Development of Indigenous Knowledge: A New Applied Anthropology”. Current Anthropology, 39(2). 
STIRRAT, R.L. 1996. "The New Orthodoxy and Old Truths: Participation, Empowerment and Other Buzz Words”. In: BASTIAN, Sunil \& BASTIAN, Nicola (eds.). Assessing Participation: A Debate from South Asia. Delhi: Konark Publishers. . 2000. "Cultures of Consultancy". Critique of Anthropology, 20(1).

STONE, L. 1989. "Cultural Crossroads of Community Participation in Development: A Case from Nepal”. Human Organization, 48(3).

SWAAN, Abram de. 1988. In care of the State. Health Care, Education and Welfare in Europe and the USA in Modern Era. New York e Oxford: Oxford University Press.

TONNIES, F. 1957 [1887]. Community \& Society. (Gemeinschaft und Gesellshaft). New York: Harper \& Row.

VILLA ROJAS, A. 1948. "El Papel de la Antropología en las Obras del Papaloapan, México”. América Indígena, 8(4).

WALTON, R.E. \& GAFFNEY, M.E. 1991. "Research, action and participation: the Merchand Shipping case”. In:WHYTE, W.F. (ed.). Participatory Action Research. Newbury Park-California: Sage Publications.

WENDT, R.F. 2001. The paradox of empowerment: Suspended power and the possibility of resistance. Westport: Praeger.

WHITE, S.C. 1996. "Depoliticising Development: The uses and abuses of participation". Development in Practice, 6(1).

WOOST, M.D. 1997. "Alternative Vocabularies of Development? 'Community' and 'Participation' in Development Discourse in Sri Lanka”. In: GRILLO, R.D. \& STIRRAT, L.R. (eds.). Discourses of Development. Anthropological Perspectives. OxfordNew York: Berg. 


\section{Resumo}

$\mathrm{O}$ artigo concentra-se nas representações da 'alteridade cultural' no âmbito de discursos, propostas e intervenções para o desenvolvimento das populações etnicamente diferenciadas que norteiam o atual 'campo do desenvolvimento', com particular atenção à atuação e ao papel do Banco Mundial. A análise tem como foco o uso de conceitos como 'participação', 'empoderamento', 'comunidade', 'capital social' e 'indigenous knowledge' nos documentos do Banco Mundial. Procura-se individualizar, deste modo, os mecanismos de construção da - e intervenção sobre a - realidade, com os quais operam o Banco e agências similares, para avançar hipóteses, e propostas metodológicas relativas às oportunidades que os processos de interação social, conseqüência de particulares formas de intervenção, oferecem à análise das relações sociais.

\section{Palavras-chave}

Desenvolvimento, participação, empoderamento, comunidade, capital social, indigenous knowledge, Banco Mundial.

\begin{abstract}
The article focuses on representations of 'cultural alterity' as they are formulated in the discourses, proposals and interventions for the development of ethnically differentiated peoples, which permeate the 'field of development.' Particular attention is devoted to the production of the World Bank, for its leading role in the field. The analysis concentrate on the use of concepts like 'participation,' 'empowerment,' 'community,' 'social capital' and 'indigenous knowledge,' as they are elaborated in the document of the World Bank. The objective is the individuation of the mechanisms of construction of - and intervention over - reality, with which the World Bank and similar agencies operate, and to formulate hypothesis and methodological proposals about the opportunities that the study of processes of social interaction resulting from specific forms of interventions, offers to the analyses of social relations.
\end{abstract}

\section{Key words}

Participation, empowerment, community, social capital, indigenous knowledge, World Bank. 